\title{
Odontogenic Choriostoma in buccal mucosa associated with suspected Goldenhar Syndrome
}

\author{
Prashant M Battepati ${ }^{1}$, Priyanka Gupta ${ }^{2}$, Bhari Sharanesha Manjunatha ${ }^{3 *}$ and Bheema Setty Manasali ${ }^{4}$ \\ ${ }^{1}$ Department of Preventive Dental Sciences, University of Taif, KSA \\ ${ }^{2}$ Consultant Pediatric dentist, India \\ ${ }^{3}$ Department of Oral Biology, Faculty of Dentistry, University of Taif, KSA \\ ${ }^{4}$ Department of Fixed Prosthodontics, Faculty of Dentistry, University of Taif, KSA
}

\begin{abstract}
Presence of teeth or tooth like masses at unusual sites of perioral structures like maxillary sinus, nasal cavity, ear, lip etc have been occasionally reported. But presence of fully developed dental structures with supporting skeletal tissue at non tooth bearing areas is extremely rare entity. In this report a similar case of presence of supplemental dental tissue along with supporting skeletal structure at buccal mucosa affecting facial symmetry which was associated with suspected Goldenhar Syndrome is presented. Report of such condition is extremely scanty in available literature and has been termed as OdotogenicChoriostoma by certain authors.
\end{abstract}

\section{Background}

Presence of tooth or tooth like structures at extragingival sites is not uncommon. Various extra gingival sites are reported for presence of such kind of structures like nasal cavity, maxillary sinus, ear, tongue as well as mandibular condylar and coronoid process. Presence of such structures may cause malocclusion, difficulty in breathing, incomplete articulation and speech alteration. Some of them are diagnosed early whereas some remain subclinical and diagnosed incidentally on radiograph. Confirmatory diagnosis for such structures is made by co relating clinical, radiographic and histological examination.

Presence of tooth like structures at unusual site is considered ectopic and their presence in soft tissue is seldom observed. The term "choriostoma" has been proposed for such kind of structures which are histologically normal for a part of body except at the site where it is located [1]. Primary classification of choriostoma has been proposed based on its clinical and histomorphologic features like salivary gland choriostoma, osseous and cartilaginous choriostoma, glial and gastric choriostoma etc [2]. Osseous and cartilageous types of choriostoma are most commonly seen in oral cavity [1]. For presentation of such lesions with dental component as well as its location on extra gingival site, term 'odontogenic choriostoma' seems to be appropriate. We present an unusual case of an 8 year old girl with presence of tooth like structures in right buccal mucosa with supporting bony extension from right maxillary posterior region associated with suspected case of Goldenhar syndrome, for which term odontogenic choriostoma is used.

\section{Case presentation}

An 8 year old girl reported to department of Pediatric dentistry,with chief complaint of presence of decayed teeth in right and left back region of lower jaw with no associated symptoms.

On extra oral examination, loss of facial symmetry was evident (Figure 1). There was presence of diffuse swelling extending from right corner ofmouth to tragus of right ear. Superiorly, it was extending to infraorbital region of right eye and inferiorly till angle of the mandible on same side. There was no obliteration of nasolabial fold seen. Right corner of the mouth was appeared to be stretched out and with presence of faded groove running (resembling a surgical scar) from right corner of mouth, which was merging with the cheek after travelling a distance of $1 \mathrm{~cm}$. On palpation, swelling was non-tender and firm in consistency. Seemingly child was not much concerned about the asymmetrical face.

On intra oral examination: Patient's mouth opening was sufficient and she was able to articulate her teeth. A mixed dentition stage was seen with erupted $11,21,16,26,36,46$, and $31,32,41,42$ in oral cavity. There was presence of proximal decay with respect to mandibular right and left first primary molars.

While examining intra oral soft tissues, a supplemental tooth like structure was revealed on right buccal mucosa distal to permanent $1^{\text {st }}$ molar which closely resembled the morphology of permanent maxillary molar. With respect to tooth like mass, almost two third of crown was exposed in oral cavity which was facing permanent first molar (Figure 2). On palpation, surrounding mucosa was apparently normal and there were no signs of inflammation or infection. Bidigital palpation confirmed that the structure was firmly adherent to the underlying tissues as it was firm and immovable.

On further questioning, parents revealed that the swelling was first noticed few years back and gradually increased to present size. There was no history of trauma. Patient's medical history was significant as she had visited pediatricianand ENT specialist when she was 2 years old. Reports by pediatrician revealed presence of

${ }^{\star}$ Correspondence to: Manjunatha BS, Associate Professor, Department of Oral Biology, Chairman, Scientific Presentation Committee, Member, Examination Unit, Faculty of Dentistry, Taif University, Kingdom of Saudi Arabia, E-mail: drmanju26@hotmail.com

Received: April 09, 2019; Accepted: April 25, 2019; Published: April 29, 2019 


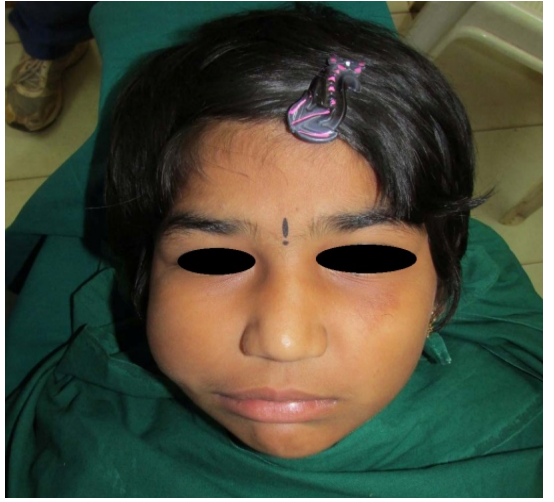

Figure 1. Frontal view of patient showing facial asymmetry on right side

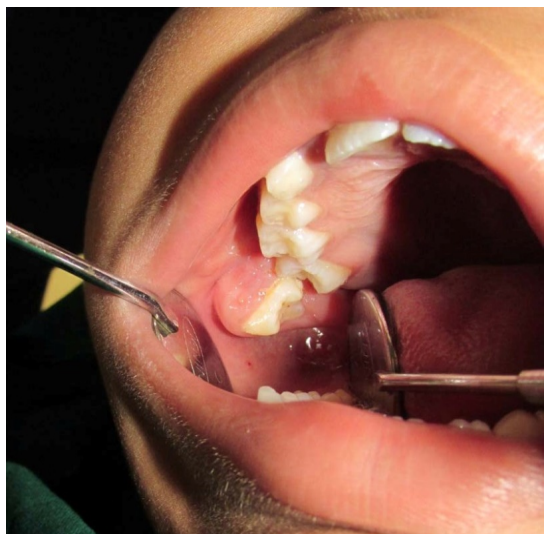

Figure 2. Intra-oral view showing supplemental tooth like structure on right buccal mucosa distal to permanent $1^{\text {st }}$ molar

multiple ear abnormalities and ear tags, macrostomia, right eye anomalies and hearing impairmentfollowed by advise for $\mathrm{x}$-ray for cervical spine, echocardiography and test for hearing assessment. Investigatoryreportsby department of audiology from a hospital were accessed which revealed that on performing BERA test(Brainstem Evoked Response Audiometry)there was moderate hearing impairment with respect to left ear and right ear was normal. Whereas, reports of ECG and chest $\mathrm{x}$-ray had shown no abnormalities.One of the medical reports of the childalso showed a provisional diagnosis of Goldenhar syndrome at age of 2 years.

In order to get a pan oral view and to rule out presence of any additional teeth, OPG (Orthopantomogram) was advised. The OPGrevealed mixed dentition stage (erupted permanent central incisors, molars and primary canines and molars)and the developing tooth buds of permanent canines, premolars and second molarsalong with two radiopaquemasses with radio density comparable with neibhouring teeth in maxillary right quadrant (Figure 3). In addition a lateral cephalogram (Figure 4) was also made, Nevertheless due to superimposition, detailed morphology could not be ascertained in both the radiographs. Hence 3 dimensional imaging using Digital volumetric tomography (DVT) was advised for the right posterior maxillary region.

DVT images revealed presence of two tooth like structures with well developed internal morphology (pulp chamber and root canals) located distal and buccal to maxillary right $1^{\text {st }}$ permanent molar. One among them was partially erupted whereas other was completely embedded into bony stalk which appeared to be originated from posterior most part of maxillary bone (Figure 5).
Based on the available evidence the lesion was diagnosed as Odontogenic choriostoma and surgical excision of the lesion was planned, however surgery could not be performed as parents of the child did preferred to wait and delay the surgical intervention.

\section{Discussion}

This report has presented a case with erupted supplemental tooth in right buccal mucosa with bony stalk. Although, presence of this was a diagnostic enigma because of its unusual location and close resemblance with normal morphology of tooth.

There are various terminologies used in literature for such kind of peculiar structures like irregular eruption, ectopic tooth, ectopic odontoma [3] and odontogenic choriostoma [4]. The term ectopia is used to designate a condition where a tooth or tooth like structure is located or erupts in a place remote from the normal site [3]. The present case showed eruption of tooth-like structure from the right buccal mucosa; hence the term ectopic can be used.

Noroozi and Arora described a similar case of mature tooth like molariform type in buccal mucosa with a bony stalk for which they proposed the term 'odontogenic choriostoma'. The term odontogenic choriostoma by definition is a mass formed by the faulty development of tissue of a type not normally found at that site with inherent growth potential. Choriostoma have a composition limited to only 1 or two germinal layers [4].

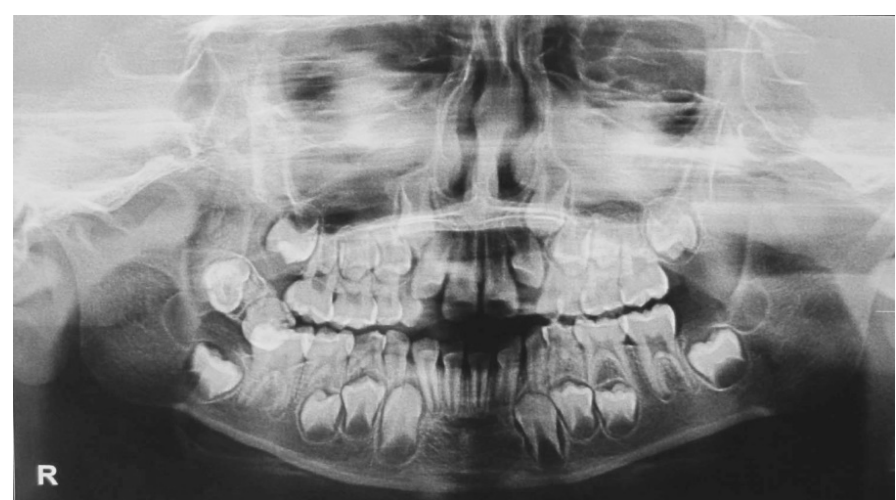

Figure 3. Orthopantomograph revealed two radiopaque masses with radio density comparable with neighbouring teeth in maxillary right quadrant

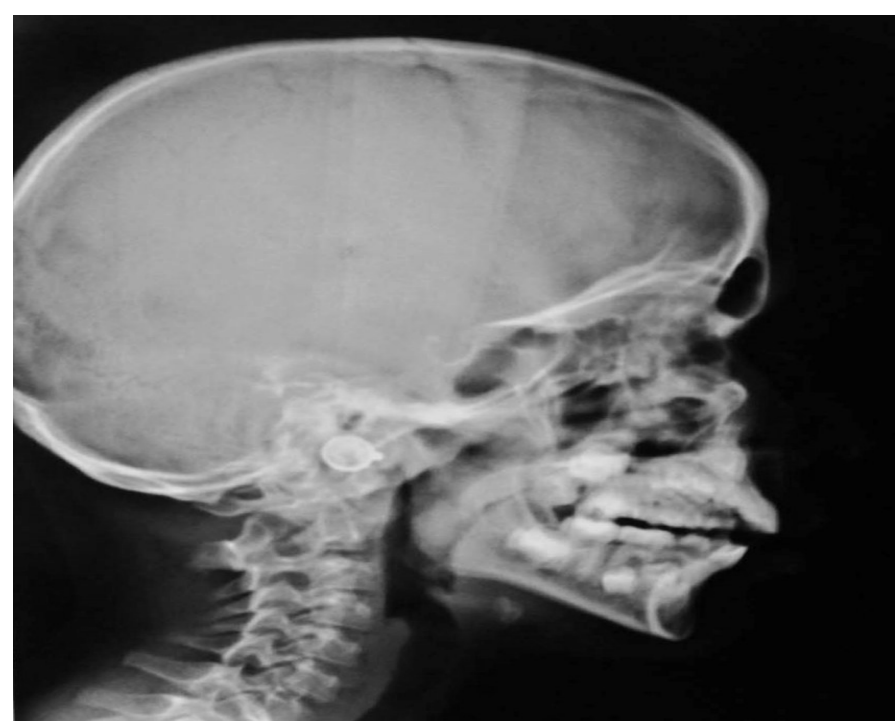

Figure 4. Lateral cephalogram of the patient 


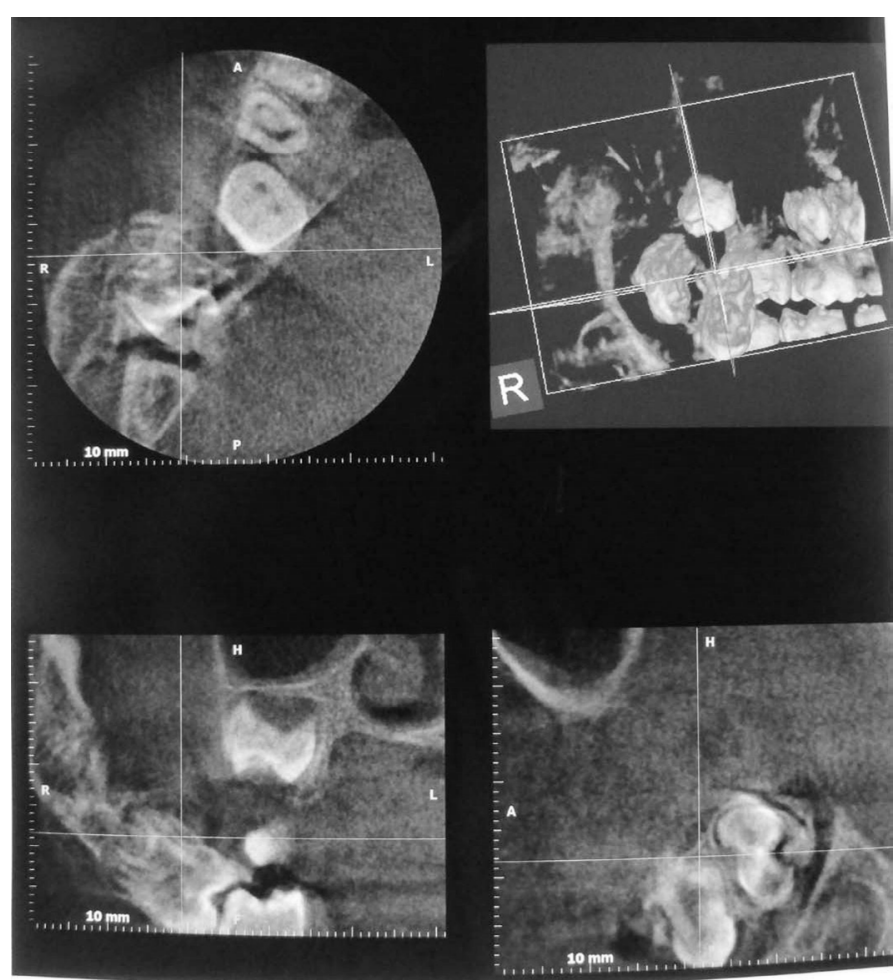

Figure 5. On DVT a bony stalk containing two teeth like structures can be appreciated

The most common types of intra oral choriostoma are either osseous (osteomas) or cartilaginous (chondromas) and occur in the tongue [1]. They present as firm smooth sessile or pedunculated nodules usually symptomless, with increased predilection for women. There are only few cases have been reported of choriostoma with dental origin.

In 1971 Kroll et al published 9 cases of ectopic bony lesions of the oral cavity and called them osseous choriostoma [5]. A case of osseous choriostoma was found in buccal mucosa of a 28 years old woman with Klippel Feil syndrome, but no association with a tooth was reported and lesion consisted of lamellar bone, osteocytes and haematopoietic tissue [6]. In 1977 Bakry reported a case of 9 year old girl with Klippel Feil syndrome. The lesion consisted of a geminate tooth surrounded by follicle. The mass was enveloped by proliferative fibrous tissue and foci of cartilage \& bone but without any bony extension as seen in present case [7].

The observation of in situ tooth formation in areas outside the dental arches has reflexively led to the primary consideration of choriostoma. On reviewing the previous literature it was found that odontogenic tissues are not seen at these sites [8]. It should be noted that, with the exception of a single case of a tooth in the upper lip[9] tongue[1] or Wharton's duct[10], the buccal mucosa is only a known extragingival location in which a variety of odontogenic lesions can be encountered[8] .

The etiology of intraoral osseous choriostoma as of yet has not been established. One theory hypothesizes that they occur as embryologic developmental abnormalities with entrapment of embryonal rest or multipotential cells during fetal development [11]. Lesions in other areas including anterior or lateral tongue and buccal and palatal mucosa have been postulated to arise from post-traumatic ossification [12]. The present case did not give any history of trauma.

The apparent buccal proclivity of such lesion as in present case infers the developmental affinity between the dental and vestibular laminae; the former differentiates toward the enamel organ, and the latter is a primordium of the buccal sulcus and mucosa. It has long been recognized that both structures evolve independently as epithelial thickenings. Recently, it have been revealed that they have a common origin and fuse together, reflecting the latent odontogenic potential of vestibular lamina [8]. So, it can be guessed that buccal mucosa might also form a basis for aborted attempts at odontogenesis under exceptional conditions in postnatal life.

Management usually consists of surgical resection of tooth like structure along with bony extension and the prognosis after treatment appears favorable, with scant relapse.There are few reports of recurrence after this treatment modality. Long and Koutnik reported a case of recurrence 12 years after surgical excision of buccal osseous choriostoma [13]. As in this case treatment was not performed due to parent's unwillingness.

The characteristic features of Goldenhar syndrome include epibulbar dermoids, auricular abnormalities, preauricular appendages and fistulae, hypoplasia of malar bones, mandible and zygomatic arch. Few authors also reported association of macrostomia, vertebral/ cervical abnormalities, malaocclusion and other dental abnormalities. Disturbances of central nervous system,visceral,cardiac and genitourinary abnormalities also have been reported [15].

In present case though patient's history is significant with probability of goldenhar syndrome but when patient reported to us there were no such clinical distinguishing features suggestive of Goldenhar syndrome except for a surgical scar on right corner of mouth probably due to surgical correction of Macrostomia and history of surgery near ear region. Hence author chose to refer this case as "suspected case" of Goldenhar syndrome.

The case presented in this report was not associated with any history of trauma or familial tendency. The exact etiology of this lesion remains unknown. To our knowledge this is a first case presentation of unilateral odontogenic choriostoma consisting of multiple teeth like structures with associated bony stalk/ extension in a child with suspected case of Goldenhar syndrome.

\section{References}

1. Gopalakrishnan R, Koutlas IG, Schauer GM, Schnitker G (2009) Dental (odontogenic) choristoma of the tongue. J Oral Maxillofac Surg 67: 1135-1138. [Crossref]

2. Chou LS, Hansen LS, Daniels TE (1991) Choristomas of the oral cavity: a review. Oral Surg Oral Med Oral Pathol 72: 584-593. [Crossref]

3. Venigalla A, Guttikonda LK, Nelakurthi H, Babburi S, Pinisetti S, et al. (2015) Ectopic compound odontoma in the buccal mucosa: report of a rare case. Case Rep Dent 2015 835171. [Crossref]

4. Ide F, Mishima K (2012) What is an odontogenic choristoma? J Oral Maxillofac Surg 70: 3-4. [Crossref]

5. Noroozi AR, Arora E (2011) Odontogenic choristoma: report of a case. J Oral Maxillofac Surg 69: 3006-3009. [Crossref]

6. Krolls SO, Jacoway JR, Alexander WN (1971) Osseous choristomas (osteomas) of intraoral soft tissues. Oral Surg Oral Med Oral Pathol 32: 588-595. [Crossref]

7. Gaitán-Cepeda LA, Quezada-Rivera D, Ruíz-Rodríguez R (2003) Osseous choristoma of the oral soft tissue. Case report. Med Oral 8: 220-223. [Crossref]

8. el sedfy Bakry N (1977) An ectopic odontome in the cheek. Oral Surg Oral Med Oral Pathol 43: 583-584. [Crossref]

9. Ide F, Kikuchi K, Miyazaki Y, Mishima K, Saito I, et al. (2010) Keratocyst of the buccal mucosa: is it odontogenic? Oral Surg Oral Med Oral Pathol Oral Radiol Endod 110: e42-47. [Crossref]

10. Rion CL (1930) Tooth in upper lip: report of case. J Am Dent Assoc 17: 2295 
11. Gupta DS, Tandon PN, Sharma S, Jurel SK, Majumder K (2011) Intraglandular tooth-rare case report of tooth in submandibular salivary gland duct. $J$ Oral Maxillofac Surg 69: e305-307. [Crossref]

12. West CB Jr, Atkins JS Jr (1988) Choristomas of the intraoral soft tissues. Otolaryngol Head Neck Surg 99: 528-530. [Crossref]

13. Sookasam M, Philipsen HP (1986) The intra-oral soft tissue osteoma: report of two cases. J Dent Assoc Thai 36: 229-234. [Crossref]
14. Long DE, Koutnik AW (1991) Recurrent intraoral osseous choristoma. Report of a case. Oral Surg Oral Med Oral Pathol 72: 337-339. [Crossref]

15. Dali M, Chacko V, Rao A (2009) Goldenhar syndrome: A report of a rare case. Journal of Nepal Dental Association 10: 128-130.

Copyright: (C2019 Battepati PM. This is an open-access article distributed under the terms of the Creative Commons Attribution License, which permits unrestricted use, distribution, and reproduction in any medium, provided the original author and source are credited. 